\title{
Experiences of Culturally and Linguistically Diverse Parents with Deaf Children during the Individualized Educational Plan Process
}

\author{
Angela K. Trahan*, Ju-Lee A. Wolsey, M. Diane Clark \\ Department of Deaf Studies and Deaf Education, Lamar University, Beaumont, TX, USA \\ Email: *aktrahan@gmail.com
}

How to cite this paper: Trahan, A. K., Wolsey, J.-L. A., \& Clark, M. D. (2018). Experiences of Culturally and Linguistically Diverse Parents with Deaf Children during the Individualized Educational Plan Process. Psychology, 9, 427-459.

https://doi.org/10.4236/psych.2018.93027

Received: January 25, 2018

Accepted: March 27, 2018

Published: March 30, 2018

Copyright ( 92018 by authors and Scientific Research Publishing Inc. This work is licensed under the Creative Commons Attribution International License (CC BY 4.0).

http://creativecommons.org/licenses/by/4.0/

\begin{abstract}
For effective educational and language planning for a deaf child, it is important that parents and the child, if they are old enough, understand their rights and the processes involved in developing an Individualized Education Plan (IEP). The IEP provides an important "road map" for deaf children to receive appropriate services for effective educational outcomes. This qualitative study focused on understanding the experiences, both positive and negative, faced by parents of deaf children going through the IEP process. To better understand parents' experiences and perspectives, a grounded theory-based approach was used with a three-step systematic procedural analysis to identify themes, axial codes, and the core category. Based on the data analysis from the interviews, eight themes and three axial codes were identified, leading to the overarching theme of "giving parents a voice". This study provides insights and recommendations to support parents, deaf children, and school personnel in regards to their understanding of an efficient IEP process.
\end{abstract}

\section{Keywords}

Deaf, Parents, Individualized Education Plan, Grounded Theory, Experiences

\section{Introduction}

An Individualized Educational Plan (IEP) serves as an important "road map" for services, evaluation, and placement, as required by the Individuals with Disabilities Education Act (IDEA) for all children with disabilities and their parents (Gartin \& Murdick, 2005). The IEP mandate insures that all of these children with disabilities get a free and appropriate education, known as FAPE. To obtain the most effective outcomes for these students, educational specialists work to 
include parents in the IEP process to improve their children's academic outcomes (Underwood, 2010). Therefore, it is important to know what parents understand about the IEP process; this information will lead to the development of strategies that allow parents to feel comfortable and confident about their involvement in the process. Then from the school personnel perspective, it is critical to understand barriers that tend to disempower parents in the IEP process.

The IEP team usually consists of parents, their child if appropriate, teachers, administrators, assessment specialists, and local educational agency representatives. Implementation of required parental involvement, was one of the measures the federal government used to ensure that the school personnel informed parents about IEP meetings through letters, phone calls, or emails. Parents may also participate in IEP meetings through teleconferences or videoconferences (More \& Hart, 2013). Moreover, strategies to incorporate parents in the IEP goal planning, including how to prepare them to effectively participate in the process and ensure effective cross-cultural communication, are part of the recommendations for best practices to serve the needs of children with disabilities. These policies empower parents to advocate for their children (Lo, 2012) and be knowledgeable about their rights and responsibilities.

The concept of parental rights, including procedural due process, was established by the Education for All Handicapped Children Act (EAHCA) of 1975 (Maydosz \& Maydosz, 2012). This crucial piece was maintained in all of the re-enacted laws, including the current 2004 Individuals with Disabilities Education Improvement Act (IDEIA; Maydosz \& Maydosz, 2012). This policy is intended to help parents understand their rights as part of the IEP team. Procedural safeguards ensure that the decisions made by the IEP team protect parents' rights and provide an effective FAPE environment for their child. These rights are the appeal procedures available to parents if they disagree with the process.

Parents have the right to agree or disagree with the decisions established during the IEP process (Wright, Wright, \& O'Connor, 2010). However, many parents do not receive the information needed to understand their rights, which are protected by federal laws (Knight, 2010). Often, parents have insufficient knowledge of these rights, including the fact that they have the ability to make the final decision on IEP changes. This process is frequently overwhelming for parents and may limit their motivation or willingness to attend IEP meetings.

Parents, who have children with disabilities, frequently report being highly dissatisfied with IEP meetings (Shah, 2012). Knowledge of the IEP process and the level of parental satisfaction are ongoing issues needing to be addressed in order to create a positive atmosphere between parents and schools (Shaffer, 2010). Addressing the needs of parents with deaf ${ }^{1}$ children is even more complicated, and presents unique areas for consideration. But unfortunately, little re-

${ }^{1}$ The term, "deaf", is being used in an all-inclusive manner to include people who may identify as Deaf, deaf, deaf blind, deaf disabled, hard of hearing, late-deafened, and hearing impaired (National Deaf Center on Postsecondary Outcomes, 2017). Deaf culture is capitalized, as are a few other ideas, to reflect positionality within a signing Deaf-centric community. 
search has examined parents' experiences and knowledge of the IEP process for deaf children (DesGeorges, 2013).

\subsection{The IEP Process in Terms of Least Restrictive Environments}

IDEA focused on providing children with disabilities educational environments where they were able to be with their peers, who do not have disabilities, to aid in their social emotional development (Aldersley, 2002). This policy was referred to as the least restrictive environment (LRE) (Aldersley, 2002). This specific policy has led to many children being placed in general education, or mainstream placements, for at least part of the day (Hyatt \& Filler, 2011). This placement is often a misguided, but well intentioned decision, which frequently violates the deaf child's civil rights.

In response to this placement, the Conference of Educational Administrators of Schools and Programs for the Deaf (CEASD) reframed LRE as a "language rich environment". This shifting of the lens was to provide educational placements that promote the social, linguistic, and academic development for all deaf children (CEASD, 2012). This campaign was called Child First (CEASD, 2012), which is the idea that general education often places a deaf child in an isolated environment, such as a mainstream program in the local public school. This placement limits their ability to become a healthy, cognitively, well-developed child. CEASD's perspective highlights a context which embeds the deaf child in a milieu of visual language which can be "overseen" from adults, peers, and staff who are using sign language. We know that "overhearing" language increases vocabulary develop (Hart \& Risely, 1975, 1989); therefore LRE in the Child First campaign emphasizes this same natural benefit from a visually rich language environment. The Child First campaign advocates that the traditional definition of LRE deprives deaf children of the ecological niche that most benefits their linguistic and social emotional development (Ceci, 1990).

\subsection{Parents of a Deaf Child and IEP Meetings}

Debates about the best placements for a deaf child often leave parents extremely confused. Most deaf children are born to hearing parents (Karchmer \& Mitchell, 2003), who have never met a deaf adult (Benedict, 2013). Therefore educational placements are critical but unknown territory for these hearing parents, who are trying to find appropriate information regarding their deaf child's development. Many factors are necessary for these parents to try to understand and this information impacts their child's placement goals.

Factors related to IEPs for deaf children include how to support their linguistic needs, the severity of their hearing loss, the potential for use of any residual hearing, the student's academic level, as well as their social, emotional and cultural needs. All of these issues are vital when deciding on the placement of a deaf child (Hyatt \& Filler, 2011). The decisions related to school placement for deaf children may include public schools, private institutions, special classes, and 
state schools for the deaf. These types of placements decisions occur during the IEP meeting between the school personnel and parents (Aldersley, 2002).

However, placement decisions were often perceived by Aldersley (2002) as unreasonable due to the interpretation of LRE, which differs from state to state. Even more, Aldersley (2002) argued that there is undue harm placed on deaf children through deprivation of their linguistic, academic, social, emotional, and cultural needs. For example, in Hendrick Hudson Central School District v. Rowley (1982) (McKay, 2013), a deaf student, through her parents, claimed she was entitled to quality education under the IDEA clause. Her parents filed a suit against the school district claiming that the district was in noncompliance with IDEA by not providing an education that was meaningful for their deaf child (Darden, 2009). The school district argued that the quality of interpreters, which were provided to the deaf child, were adequate but her parents disagreed (Darden, 2009). The question, as debated by Darden (2009), focused on the effectiveness of interpreting services provided by the school system; the issue at hand was whether these services were meaningful or merely pro forma to satisfy the legal requirements. This issue of appropriate services to satisfy FAPE continues to be controversial in the legal arena.

Additionally, in 2000, the 11th Circuit Court found in favor of two students who had been placed in a local special education classroom without a teacher of the deaf (Easterbrooks, Lytle, Sheets, \& Crook, 2004). The decision entitled the family to up to $\$ 2.5$ million dollars from the school system. The judge stated that these students were denied their legal rights and their case highlights the issues that can occur with the varying definitions of LRE. After 2004, the requirement for the IEP teams to consider the language and communication needs of the deaf child was not specifically part of the re-enacted IDEIA.

With the 2004 IDEIA, the school administration had the opportunity to redefine the multidisciplinary team to better identify deaf children's academic, linguistic, socio-emotional, and cultural needs (Easterbrooks et al., 2004). This team should include two or more members with extensive experience in the needs of deaf and hard of hearing students, as well as parents (Easterbrooks et al., 2004). These issues highlight the importance of parental involvement and their ability to comprehend IEP policies and procedures during meetings to be sure that their child's educational placement is the most effective and that the child's needs are placed before the budgetary concerns of the school.

Pittman \& Huefner (2001) discussed that families who prefer a bilingual-bicultural education with the utilization of American Sign Language (ASL) and written English language were frequently denied this educational placement when IDEA was reauthorized in 1997 and additional amendments were added in 1999. They write, "however, as a result of the amendments in 1997 that no longer required a focus on language and communication, it has become more difficult to place deaf children in an appropriate linguistic environment" (Pittman \& Huefner, 2001: p. 191). These issues continue even today but became more com- 
plicated with the addition of the 2001 No Child Left Behind Act (NCLB).

\subsection{NCLB}

IDEA and NCLB are two of the most recent laws scrutinized by the circuit courts. These courts decisions focused on defining the legal standard for appropriate placements for the child's benefit, as well as the requirements related to the responsibility of the IEP team to provide strategies, placements, and assessments to insure the child's progress toward meeting specified goals (Etscheidt, 2012). IDEA was passed in 1990 but NCLB superseded this law in 2001 with modifications to the IDEA, which were then combined as a new law, IDEIA, in 2004 (Moores, 2005). IDEIA was implemented to measure academic progress towards state standards under NCLB (Moores, 2005). One major component of this change was how schools measure adequate yearly progress (AYP). Importantly, deaf students were then included in these mandated assessments. Moores (2005) determined that these new laws created conflicts in the area of deaf education and that AYP was an inappropriate measure for the success of students in deaf schools and programs. As noted by Steffan (2004), requirements for deaf students, who attend schools for the deaf, cannot be compared to students in public schools because they are a low incidence population. Therefore, many deaf programs were exempted from being included in the statistics required to be submitted by each school. Nonetheless, Moores (2005) credited NCLB for raising the expectations for deaf children, which led to the increased passing of standardized state-level criterion-referenced tests among deaf children.

Educators need to set aside the jargon of federal regulations and focus on each child's needs by identifying appropriate academic standards, such as vocabulary acquisition, reading, and writing. They need to define the desired outcomes of instruction, identifying instructional activities, and target specific objectives on the IEP so deaf children can academically, linguistically, socio-emotionally, and culturally thrive in and out of the classrooms (McBride \& Goedecke, 2012). In this way, we are putting the child first. Diversity is also important for families with a deaf child, who may then be multilingual.

\subsection{Parents and the IEP Process}

Demographic data for parents and deaf children from culturally and linguistically diverse backgrounds present an alarming need for further research on the identification of barriers encountered during the IEP process. The cultural representations, values, and norms were variables explored by Trainor (2010b) to devise strategies regarding how to solicit more involvement from parents who are culturally and linguistically diverse.

Parents with culturally and linguistically diverse backgrounds may identify themselves with one, two, or more cultures and languages (Peralta, 2013). These parents maintain communication with their children in their home language and value their traditional cultures, but they experience problems with the school 
personnel due to barriers in language and a lack of diverse cultural knowledge on the part of school personnel. These parents wanted the best for their children, but insufficient collaboration from school personnel is a barrier (Peralta, 2013). The challenge for these diverse parents is that they have limited English proficiency. As a result, the information about procedural safeguards, the whole IEP process, and the selection of educational goals can be inaccessible to these parents. Interpreters typically are involved to provide interpretation for parents during the IEP meetings; but the system frequently does not take into consideration the cultural approach that parents with these kinds of backgrounds need (Jung, 2011).

Parents' perceptions, different communication styles, and ethical issues with interpreters, as well as structural values imposed by school professionals' attitudes were identified as barriers for diverse parents (Jung, 2011). Insensitivity towards parents' values and beliefs led to miscommunication, lower expectations of academic achievement, and incorrect diagnosis of disability (Jung, 2011). Many parents are unaware of their rights to bring an advocate during the IEP meetings. As the role of an advocate was not defined in IDEA, school personnel are not required to inform parents that they can bring advocates to the IEP meetings. The definition on the role of an advocate needs to be diligently re-evaluated in the IEP procedural safeguards and clearly stated with language that parents from diverse backgrounds can understand.

\subsection{Parents' Appeal for Advocacy}

Advocacy skills among parents are of great concern in IEP meetings (Trainor, 2010b). Evidence of parent satisfaction occurred when the IEP team respected parents and their values of focusing on their child's welfare as their top priority and their child's disability as a secondary emphasis (Byington \& Whitby, 2011). Also, they became more comfortable during IEP meetings after they were educated about the laws and regulations (Byington \& Whitby, 2011). Parents' roles as advocates, disability experts, strategists, and promoters of systematic changes were some of the most frequent themes identified by Trainor (2010a). However, cultural and linguistic barriers inhibited parents from fully assuming these roles during IEP meetings. Trainor (2010a) stressed advocacy as an opportunity for parents with diverse cultural and linguistic backgrounds to assist in the evaluation of the disabled child's abilities to meet IEP goals.

\subsection{Parents' Levels of Satisfaction with the IEP Process}

Shaffer (2010) identified the need to improve the IEP process with increased participation from parents in order to promote a positive atmosphere and a chance for students with disabilities to excel in academics. They investigated overall levels of parental satisfaction with the IEP process, as well as the effects of federal laws on parental involvement during the IEP process (Shaffer, 2010). Shaffer (2010) noted that parental levels of satisfaction were higher when they 
were more involved with the IEP process but noted that parents felt that the IEP teams focused more on the child's disability rather than the whole child. This lead Shaffer (2010) to recommend a need for open communication and collaboration between parents and educators.

Cawthon \& Caemmerer (2014) investigated parental expectations of their deaf children's education and assessed their levels of satisfaction of the IEP process. They found that $36 \%$ of the parents expected their deaf child to successfully complete a bachelor's degree, while $6 \%$ did not expect their deaf child to achieve more than a vocational rehabilitation placement (Cawthon \& Caemmerer, 2014). Following up on these expectations, they asked about parental satisfaction with the IEP process. Parents' were not highly satisfied in terms of understanding their legal rights, had low involvement in the meeting, but reported that they comfortable during IEP meetings. These parents reported that they could find resources to help their child but felt that the IEP team was competent.

\subsection{The Conundrum of Communication within Deaf Education}

As mentioned earlier, most deaf children (90\%) have hearing parents (Karchmer, \& Mitchell, 2003). As noted by Solomon (2012), this difference frequently creates issues with identity, as most hearing parents want their children to grow up with their own values, including their home language. Solomon (2012) discussed this conflict as one of vertical (from parent to child) versus horizontal (from deaf community to deaf child) identity development. Initially, the conflict leads to a crisis for the parents in trying to make a decision about their child's language "choice"; should they use hearing technologies like digital hearing aids and cochlear implants and focus on spoken language, or should they select a sign language. In attempts to bridge this divide, many types of communication modalities and strategies have been developed and implemented in various ways.

The choice of communication options or strategies can be thought of as a continuum that ranges from a natural sign language, i.e., ASL, to a natural spoken language, i.e., English. The continuum can be closer to ASL, which is a pidgin that is a grammatically simplified strategy for communication among groups that do not share a common language, or closer to English, using invented codes to create English on the hands (Belt, 2013). This continuum ranges from ASL to Pidgin Signed English, to Simultaneous Communication, to Total Communication, to Signed English, Sign Supported English, Cued Speech, and ends with Spoken English (Leigh \& Andrews, 2017).

Given this wide variation in communication methods, as well as two natural languages, it is not surprising that hearing parents have a difficult time understanding the best practices to use with their newly born deaf infant. They frequently make choices based on advice from individuals in the medical profession, including doctors, audiologists, and speech and language specialists. Typically they are told that they MUST make a language choice and if spoken English 
is not effective, as their first choice, they can switch to ASL later. A more effective way to help these overwhelmed parents is to discuss language preferences rather than choices; then they have an "and" rather than an "either/or" decision regarding their child's language acquisition (Benedict, 2011).

Scant peer-reviewed research has demonstrated which of these methods has a better "track record", even though there are $100 \mathrm{~s}$ of publications claiming one to be better than the other. Unfortunately, deaf education tends to be based on philosophy rather than evidence-based practices. Recent research has shown that beginning early with signing prior to the activation of a cochlear implant actually leads to better speech later (Davidson, Lillo-Martin, \& Pichler, 2014; Hassanzadeh, 2012). Therefore, it may be best to begin with providing both natural languages to the deaf child and permitting the child to decide on which language is more effective for their use. To support this hypothesis, recent peer-reviewed research has shown that an ASL/English bilingual approach leads to higher levels of academic performance (Freel et al., 2011; Hrastinski \& Wilbur, 2016).

\subsection{Purpose and Research Questions}

Given all of the issues with choice of language for deaf children, legalese within the IEP system, and some resistance from some school officials (Olivos, 2009), it is imperative that parental perceptions of IEP meetings are investigated. Therefore, the purpose of this qualitative research study was to discover experiences faced by parents of deaf children going through the IEP process. The research questions that guided this study are:

1) What were parents' experiences during the IEP process?

2) What barriers did parents perceive or experience during the IEP process?

\subsection{Positionality of the Researchers}

A deaf/hearing collaborative team, which consisted of three researchers, two Deaf and one hearing, completed this research. The primary researcher (Trahan) is a Deaf woman born to hearing parents who is strongly embedded in the Deaf community. She uses ASL as a first language and is also a former K-12 teacher in deaf education. She values a Deaf epistemology. Moreover, her personal experiences impact her perspectives and her understanding of the results. Therefore, the first author bracketed her personal experiences when interviewing parents. Her own personal experiences provided her with insights into the results obtained from these interviews. This author has experienced being on IEP teams and observing parents' levels of participation during these meetings. She has extensive experience with drafting IEP goals, facilitating IEP meetings, and communicating with parents about deaf children's progress and IEP goals. While Glesne (2006) discussed the role of the researcher, as a learner, due to novel perspectives, which may arise during the data collection, the first author acknowledges that she is also a learner because she gained new and unique perspectives from interviewing deaf and hearing parents. 
The second researcher (Wolsey) is also Deaf, uses ASL as her primary language, and was raised by hearing parents. She has an interest in supporting and empowering the lives of Deaf, Deaf Blind, and hard of hearing individuals in different contexts. In addition, she has extensive research experiences with collaborating and publishing qualitative studies.

The third researcher (Clark) is hearing and a developmental psychologist, who has been immersed in ASL and Deaf culture throughout her career. She has extensive experiences and knowledge with publishing research in the areas of cognition, reading, literacy, and Deaf culture.

\section{Method}

\subsection{Recruitment and Participants}

1) Recruitment and sampling strategy. After obtaining Institutional Review Board (IRB) approval, participant recruitment began using purposeful sampling. Purposeful sampling was used to identify and select participants based on the criteria, sample size, availability, and having experienced a phenomenon of interest (Creswell, 2013). Therefore, the primary researcher utilized purposeful sampling to investigate common experiences among deaf and hearing parents. This type of sampling or technique can "purposely inform an understanding of the research problem and central phenomenon in the study" (Creswell, 2013: p. 156). In order to effectively recruit and select participants, the primary researcher used email to distribute an invitational letter with a demographic questionnaire. They were sent to parent-teacher associations at mainstream schools and schools for the deaf in the Southwest region of the United States. In order for participants to be eligible for this study, they had to have a deaf or hard of hearing child, and a culturally and linguistically diverse background.

2) Participants. After a two-month recruitment period, eleven questionnaires were returned. Out of these eleven responses, six families (twelve parents) were selected based on their linguistic and cultural diversity. These twelve parents received a letter inviting them to be participants in the study. From the twelve parents, seven were interviewed; both parents in one family wanted to participate in the project. There were five ASL-signing parents and two Spanish-speaking parents. Four parents were hearing and three were deaf. The names of all parents were changed to maintain confidentiality and are pseudonyms in this paper. Table 1 summarized the demographic information of parents, as well as which parents (shown with $\mathrm{a}^{\star}$ ) participated in the interviews.

\subsection{Materials and Data Collection}

Data was collected from multiple sources including the demographic questionnaires and interview responses from parents. All data was documented and analyzed on the primary researcher's personal laptop utilizing Microsoft Word and Excel. The interviews were conducted using FaceTime, a video communications application, and audio on an Apple MacBook laptop. All interviews were 
Table 1. Demographic information of parents and children.

\begin{tabular}{|c|c|c|c|}
\hline $\begin{array}{c}\text { Parents/ } \\
\text { Participants }\end{array}$ & $\begin{array}{l}\text { Hearing } \\
\text { Status }\end{array}$ & Language at Home & $\begin{array}{c}\text { Educational } \\
\text { Level/Placement }\end{array}$ \\
\hline Jose $^{*}$ & Deaf & $\begin{array}{l}\text { Primary: American Sign/Sim-Com } \\
\text { Secondary: Spoken/Written English } \\
\text { Third: Minimal Spoken/Written Spanish }\end{array}$ & $\begin{array}{l}\text { High School Graduate } \\
\text { Mainstreamed }\end{array}$ \\
\hline Ana $^{*}$ & Deaf & $\begin{array}{l}\text { Primary: American Sign/Sim-Com } \\
\text { Secondary: Moderate Spoken/Written English }\end{array}$ & $\begin{array}{l}\text { High School Graduate } \\
\text { Mainstreamed }\end{array}$ \\
\hline Lorena* & Hearing & $\begin{array}{l}\text { Primary: Spoken/Written Spanish } \\
\text { Secondary: Spoken/Written English }\end{array}$ & $\begin{array}{c}\text { N/A } \\
\text { Public School }\end{array}$ \\
\hline Xavier ${ }^{*}$ & Deaf & $\begin{array}{l}\text { Primary: American Sign } \\
\text { Secondary: Written English/ } \\
\text { Minimal Spoken English }\end{array}$ & $\begin{array}{l}\text { Attended College } \\
\text { Mainstreamed }\end{array}$ \\
\hline Kiara & $\begin{array}{l}\text { Hard of Hear- } \\
\quad \text { ing }\end{array}$ & $\begin{array}{l}\text { Primary: American Sign } \\
\text { Secondary: Written English/ } \\
\text { Moderate Spoken English }\end{array}$ & Mainstreamed \\
\hline Carlos $^{*}$ & Hearing & $\begin{array}{l}\text { Primary: Spoken/Written Spanish } \\
\text { Secondary: Spoken/Written English }\end{array}$ & $\begin{array}{l}\text { College and High School } \\
\text { Graduate in Mexico }\end{array}$ \\
\hline Isabella & Hearing & $\begin{array}{l}\text { Primary: Spoken/Written Spanish } \\
\text { Secondary: Spoken/Written English }\end{array}$ & $\begin{array}{l}\text { Immigrated from Argenti- } \\
\text { na }\end{array}$ \\
\hline Irina $^{*}$ & Deaf & $\begin{array}{c}\text { Primary: Ukrainian Sign } \\
\text { Secondary: Written Ukrainian/ } \\
\text { Minimal Spoken Ukrainian } \\
\text { Third: Moderate Russian Sign } \\
\text { Fourth: Minimal Spoken/Written Russian } \\
\text { Fifth: Moderate American Sign } \\
\text { Sixth: Moderate Written English/ } \\
\text { Minimal Spoken English }\end{array}$ & $\begin{array}{l}\text { High School Graduate in } \\
\text { Ukraine } \\
\text { School for the Deaf }\end{array}$ \\
\hline Dima & Deaf & $\begin{array}{l}\text { Primary: Ukrainian Sign } \\
\text { Secondary: Written Ukrainian/ } \\
\text { Minimal Spoken Ukrainian } \\
\text { Third: Moderate Russian Sign } \\
\text { Fourth: Minimal Spoken/Written Russian } \\
\text { Fifth: Moderate American Sign } \\
\text { Sixth: Moderate Written English/ } \\
\text { Minimal Spoken English }\end{array}$ & $\begin{array}{l}\text { High School Graduate in } \\
\text { Ukraine } \\
\text { School for the Deaf }\end{array}$ \\
\hline Julia* $^{*}$ & $\begin{array}{l}\text { Hearing } \\
\text { (CODA) }\end{array}$ & $\begin{array}{l}\text { Primary: American Sign } \\
\text { Secondary: Spoken/Written English }\end{array}$ & High School Graduate \\
\hline Biological Father & Hearing & $\begin{array}{l}\text { Primary: Spoken/Written Spanish } \\
\text { Secondary: Spoken/Written English }\end{array}$ & $\begin{array}{l}\text { High School Graduate in } \\
\text { Colombia }\end{array}$ \\
\hline Stepfather & $\begin{array}{l}\text { Hearing } \\
\text { (CODA) }\end{array}$ & $\begin{array}{c}\text { Primary: American Sign } \\
\text { Secondary: Spoken/Written English }\end{array}$ & $\begin{array}{l}\text { College Graduate } \\
\text { High School }\end{array}$ \\
\hline
\end{tabular}

NOTE: ${ }^{\star S e v e n ~ p a r e n t s ~ p a r t i c i p a t e d ~ i n ~ t h e ~ i n t e r v i e w s . ~}$

video-recorded via iPad and saved in a password-protected folder by the primary researcher. The primary researcher had sole access to the videotapes and destroyed them, as well as field notes, at the completion of the final report.

1) Demographic questionnaires. To obtain a adequate sample of participants and establish rapport during the interviews, participants completed a demo- 
graphic questionnaire that was adapted from Ruppar \& Gaffney (2011). The questionnaire consisted of eight close-ended and structured questions that utilized a five-point Likert scale (Vogt, 1999). Questions focused on participants' background including, gender, hearing status, communication/language used, education, cultural and linguistic background, and interaction levels with other parents about the IEP process. These questions became the inclusion criteria to select participants for this study; therefore, participants were pre-screened prior to being selected. The questionnaire was provided in English and Spanish text to meet the linguistic needs of participants.

2) Interviews. Fourteen interview questions were originally piloted and shared with one deaf participant and one hearing participant, who were not part of the study, to obtain feedback regarding the clarity of the questions. Their feedback led to the questions being revised for clarity. The final set of interview questions included fourteen open-ended questions. Each participant (e.g., one parent) with the exception of two parents from one family completed videotaped interviews. Interview questions were drafted and adapted from Ruppar \& Gaffney (2011) and Fishman's (2012) Cultural Autonomy Theory. Questions asked about the participant's child's identity, interaction levels between participants and school staff, participants' knowledge about the IEP process, their interaction with other parents, and their experiences of navigating the IEP process.

The primary researcher interviewed four ASL-signing participants in ASL while two Spanish translators, who are hearing and hard of hearing, interviewed two Spanish-speaking participants. All videotaped interviews were transcribed to English text from ASL by the primary researcher. To transcribe spoken Spanish to English text, the hearing translator first listened to the Spanish audio recording and typed the transcript in Spanish text. Second, the hard of hearing translator reviewed the transcript in Spanish and double checked the audio recording of the interview for accuracy. Finally, the Spanish transcript was then translated from written Spanish to English text. All data was de-identified.

\subsection{Procedures}

1) Informed consent and confidentiality. After participants were recruited and selected, they confirmed their participation, and signed an informed consent that was available in English and Spanish text, as well as in ASL. The informed consent was electronically sent to participants via Survey Monkey. The demographic questionnaire was also provided in English and Spanish text using Survey Monkey. The informed consent and questionnaire were completed prior to the interviews.

2) Interviews. On the day of the interviews, the primary researcher conducted interviews through FaceTime, using an Apple Macbook. An iPad was used to record the interviews. To effectively interview two Spanish-speaking participants, the primary researcher consulted with two other colleagues who are bilingual in spoken and written English and Spanish. A hearing translator, who 
spoke with the participants via telephone, was an educator with a Masters Degree. The second translator, who used the speakerphone to ask questions, was a hard of hearing doctoral graduate in the field of deaf education. An iPad was also used to record the telephone conversation. The interviews took place away from the school premises at a location that allowed participants to feel more at ease with sharing their IEP experiences. Participants answered all of the questions with integrity and compassion, which was an assumption of the primary researcher. Individual interviews took between 45 minutes to two hours and a half; on average, the interviews were one and a half hours in length.

\subsection{Data Analytic Plan}

1) Grounded theory. Since Fishman's (2012) Cultural Autonomy Theory dissects power and phenomena within a sociolinguistic model, grounded theory was an ideal qualitative method to understand the IEP experiences of participants from diverse backgrounds. Strauss \& Corbin's (1990) grounded theory approach with the method of constant comparative analysis (CCA) (Fram, 2013) was used in this study to analyze the specific phenomenon and understand the rich corpus of data. A theory was developed through the phenomenon of interest that emerged from the data (Creswell, 2013; Strauss \& Corbin, 1990). Therefore, participants' interview responses provided rich data, insights, and recommendations to better understand their experiences during the IEP process.

2) CCA method. A three-step systematic coding process (e.g., open, axial, and selective coding) was used to reduce the data and find emerging themes and categories from interview responses (Creswell, 2013; Strauss \& Corbin, 1990). A process of memoing and analyzing the data by hand took place during the coding process where the researchers jotted down notes and ideas (Creswell, 2013; Strauss \& Corbin, 1990).

Through open coding, the interview responses were reviewed and analyzed to identify similarities and differences (Creswell, 2013; Strauss \& Corbin, 1990). Second, through axial coding, the themes were connected, compared, and categorized to establish categories (Creswell, 2013; Strauss \& Corbin, 1990). Last, selective coding was used to determine the overarching theme or core category to represent the central phenomenon, which was influenced by the categories found in axial coding (Creswell, 2013; Strauss \& Corbin, 1990). Therefore, a theory was developed from participants' experiences and perspectives to build a story (Creswell, 2013; Strauss \& Corbin, 1990).

3) Validation strategies. Member checks were used to ensure accuracy of participants' interview responses (Creswell, 2013). Participants read and approved the English transcripts to determine that they accurately reflected their interview responses. A certified ASL interpreter double checked the transcripts that were translated from ASL to English text. Two Spanish translators also reviewed the transcripts for accuracy from spoken Spanish to English text. An independent researcher had several opportunities to review the data in which the inter-rater 
reliability was $80 \%$.

\section{Results}

\subsection{Open Coding}

During the three-step coding analysis, common themes from participants' interview responses were identified first through open coding. Eight shared themes were found in participants' responses regarding their experiences and perspectives during the IEP process. These themes included: 1) rapport, 2) feedback, 3) diversity, 4) parent preparation, 5) procedural safeguards, 6) action, 7) network, and 8) advocacy.

1) Theme one: Rapport. The first theme, rapport, identified the relationship between parents and school personnel, where the majority of the IEP team members were hearing. Parents had both positive and negative experiences with rapport that included respect, accessible communication, and support during the IEP process. While the majority of participants expressed frustration with their interaction with the IEP team, they also had some positive experiences.

Some positive experiences that three participants experienced were when they valued the level of expertise offered by each member of the IEP team. Ana, a deaf participant, shared that, "the Assessment Intervention specialist, who came to see us, knows sign language". This accessible communication developed a positive rapport between the participant and the specialist. A deaf participant, Xavier, commented that "since the school interpreter already knew about Deaf culture and ASL, the translation process was much smoother". Other participants also felt that they had respect and support from the IEP team. An example shared by Jose, also a deaf participant, was that "they offered us what we requested. They offered a FM system and I said no. They highly respected us". Another example of support was mentioned by Julia, who is a hearing Child of Deaf Adults (CODA). She shared, "Oh really yes, as I went along. This [experience] really woke me up because of the vice-principal's support. That led me to understand the IEP process much more than before".

On the other hand, some participants had several negative experiences such as communication frustration and disagreements with the IEP team. An example was when a deaf participant (Xavier), stated, "My wife and I used ASL interpreters during IEP meetings, but when it boiled down to negotiations, my wife used spoken English with a vocal tone to express her concerns instead of sign language". An example of a negative experience with a lack of respect was shared by a young, hearing participant and a CODA (Julia) who commented, "I was looked down upon (inferior) by the IEP team members... [as a] young mother and they treated me differently because I didn't have a college degree". When Julia observed several more IEP meetings as an ASL interpreter, she learned how to navigate through the IEP process and became knowledgeable.

Another participant, Irina, who is a deaf mother of three deaf children, disagreed with having an IEP meeting with the team before observing one of her 
children's classrooms. Irina commented, “At the meeting, I pointed out to them that I prefer to see what was going on in the classroom first before I say something. That was my concern. So at the meeting we could discuss what I observed [in the classroom]". Irina commented:

I insisted that I wanted to able to observe Andrey in the classrooms but the staff prevented me for some perplexing reasons I did not understand. Some staff members at the school for the deaf found me annoying but I knew that I had my rights as a parent to observe my children in classes. Since I felt that I was discriminated or oppressed due to my relocation from another country and not fluent in English, I had to fight my way through and do what I felt I needed to do. I convinced the principal to transfer my older son to the Class A (advanced level) from the Class $C$ (average level) for one week, just to see how he would do. As a result, he stayed in the A group for the rest of the school year.

Another disagreement that Irina had was with the principal and the IEP team about her older child's class placement. She initially agreed with the IEP team to "hold [her older son] back one grade level so he could acquire English vocabulary words at the mainstream school". This decision was due to the fact that her family emigrated from Ukraine and was still learning English as their fourth language, but she disagreed with placing him in the lower level class rather than the more advanced class. After the discussion, he stayed in the advanced class again for the rest of the year.

Parents are not seeing school personnel as meeting them halfway. They want to work closely with the school, but are not getting open communication to become a partner with their child and the school to support academic success. When parents felt respected by school personnel, they were more satisfied with the outcome of the IEP process. They also reported a feeling that school personnel did not see them as equals, but as rather someone that did not have the necessary background to know how to work with teachers and the IEP team. Therefore, parents desired a connection to their child's school through a feeling of rapport.

2) Theme two: Feedback. The second theme, feedback, focused on parent providing feedback and advice across several areas. They included providing; a) advice to other parents who are from culturally and linguistically diverse backgrounds on how to navigate through the IEP process or understand IEP meetings, b) advice for school personnel, and c) feedback in regards to teaching strategies.

Several parents shared examples of feedback or advice that they provided to other parents from culturally and linguistically diverse backgrounds. Ana (deaf parent) shared, “The AI [Assessment Intervention] specialist really helped us by giving us [Jose and I] feedback before the IEP meetings". For example, Ana was able to ask the AI specialist about what she could request at the IEP meeting and 
asked questions, to which the AI specialist provided the answers. This feedback provided Ana with the opportunity to be more prepared with asking appropriate questions and requests at the IEP meetings. Other deaf participants, Jose and Xavier, shared similar advice and advised "parents to ask many questions and speak up for their children". They need to ask "whatever they want for their deaf children... [it] won't hurt to ask". Xavier emphasized, "I want parents to be persistent with their requests, even when the school districts may see differently". Irina, also a deaf participant, shared the following advice to other parents:

I advise parents to ask their children to explain. If they can't then parents need to ask teachers and assistants to explain more until they understand. I suggested that parents request tutoring if their children did not understand class/homework. I encourage parents to follow up on homework and provide extra instruction to their children at home, such as practicing spelling words and asking them what words mean, rather than leaving them alone.

A hearing participant, Lorena, commented that the best advice was "to always go to the $\mathrm{ARD}^{2}$ [Admission, Review, and Dismissal] meetings. I encourage them to personally go to the meeting and avoid meeting through the phone... when we go to the meeting, we can understand more things". Another hearing participant, Julia, urged parents to make sure that interpreters were fluent in ASL in their children's mainstreamed classrooms at public schools. Jose and Ana (deaf participants) advised parents to fight for their deaf children's rights, and network with other parents and deaf role models to better support their children.

In regards to the participants' advice for school personnel, Julia (hearing participant) asserted, "I want the IEP team's perceptions of deaf students to be based on their minds, not their deafness". Julia also added that the IEP team needs to "respect the parents. Trust that we want the best too". A deaf participant, Jose, emphasized:

Feedback, feedback, feedback. Give a lot of positive feedback. Be positive about and [around] [the] deaf child. A[ny] negative vibe makes parents feel resistant. Always point in [a] "POSITIVE" direction that will benefit the child's future. Encouragement! Again be positive and mention things now that will encourage them and enlighten them about what will happen with their child. Inspire them. This will make the parents be in tune and want the same outcome.

Xavier, also a deaf parent, advised school personnel "to comply with parents' requests for resources for their children... urged school districts not to underestimate or try to diminish the concerns of parents, as if their concerns are not important enough".

Some feedback in regards to teaching strategies was shared by a deaf parent, Irina, who asserted the importance of teachers and parents to have higher ex${ }^{2}$ Admission, Review and Dismissal (ARD) is used in the state of Texas, which is similar to IEP in other states (Texas Education Agency, 2014). 
pectations for deaf students. Irina also discussed ineffective teaching strategies during the IEP meeting based on her observations in her three deaf children's classrooms. Julia (hearing parent) shared:

I felt like sometimes they limit it, not willing to assess any further and only provide the minimum as required by law. They should look at what is the best for the child. If we really understand the child's unique individual needs, [then we should] not use the cookie cutter approach.

The idea of feedback focused on these parents providing advice to other parents as well as school personnel. This type of sharing empowered other parents to attend IEP meetings face-to-face and not be afraid to ask questions. In addition, parents gave advice to school personnel, much like in the theme of rapport, believing that they should be involved in their child's education. This foreshadows parents' desire for collaboration.

3) Theme three: Diversity. The third theme, diversity, referred to the parents' home language and culture, experiences of oppression, and strategies to attain equity. Access to the language preferred by parents and deaf children was a common theme. Three parents (both hearing and deaf) placed their deaf children in mainstream programs because they thought that their deaf children were intellectually equivalent to their hearing peers. Four parents (one hearing and three deaf), who were fluent in ASL, felt that their deaf children had a strong foundation in ASL from their child's elementary years at schools for the deaf. This foundation in ASL led to their academic success both at the school for the deaf and later in their mainstreamed program at a public school during high school years.

A hearing and Spanish-speaking parent, Lorena, whose first language is Spanish, shared that, "because sometimes some things are different in Spanish but... I do not know how to tell you... they are labeled different, so I do not understand, but I ask as well... so they explain [to] me and I finally understand what they are referring about". Another hearing and Spanish-speaking parent, Carlos, commented that while language is important, "English for parents may be difficult to understand what the [IEP] program is [about]... because some words are different to understand so we need certain, more advanced, concepts to understand some topics". Carlos recommended that parents ask for a Spanish translator if the IEP meeting is not $100 \%$ in their first language. As a deaf Ukrainian, Irina experienced oppression from the IEP team due to her immigrant status and having inadequate fluency in English.

Given the purposeful sampling, it is not surprising the diversity became a theme for these participants. IEP meetings can be complex with a variety of languages all needing to be managed to have vital information conveyed in ways that ensure that it is comprehensible to all members of the team. Parents are suggesting that it is easier to either not attend the meeting physically or to simply accept the school personnel's decision for many families. But those families 
who wanted their voices to be heard strongly disagreed with this idea. They were strong advocates for completely accessible information and understanding of the plans for their child's education. This theme naturally connects to the next one.

4) Theme four: Parent preparation. The fourth theme, parent preparation, described how participants did not understand the IEP process. This lack of understanding was the result of not receiving information in advance of the meeting. Parents shared that this lack of preparation also included not providing them with agendas, progress reports, or classroom observations prior to the IEP meeting. The IEP team seemed not to see a need to prepare them prior to the meetings. School personnel were inconsistent about contacting them to schedule meetings and frequently did not send progress reports. Parents reported these experiences as negative. Several examples of this lack of preparation were shared by parents.

Two participants stated that they were prepared with information prior to IEP meetings, but four other participants explained that the information was presented to them during the meetings. For example, two deaf participants, Jose and Ana, explained that the school personnel prepared them for the meeting by assigning an Assessment Intervention specialist to work with them and their deaf children. In contrast, other participants arrived at the meeting with no information about the process or what would be discussed. All six parents emphasized that attendance at the IEP meetings in person greatly benefited them with receiving more information about their child's educational progress. Parents, who were well prepared, experienced strong collaboration with the school. Lorena emphasized that she wanted to know the agenda ahead of time to know what topics would be discussed. That way, she could "be ready to ask what [she] want[s] to obtain more answers to [her] questions". As a result, parents can be more involved in the IEP meetings and support their children.

According to Irina (who is deaf), the team provided her with a written explanation of her children's progress and wanted to schedule a meeting with the teacher before the actual IEP meeting. However, she wanted to observe her children in the classroom first. Irina "prefer [red] to see what was going on in the classroom first... so [that] at the meeting, we could discuss what I observed". Irina and her husband had seen some areas that needed improvement during their observations in the classroom. Like Irina, several other participants advised other parents to observe their children in the classroom, then discuss issues with them at home to find strategies on how to maximize their education. These strategies were then listed as IEP goals during the meetings with the school personnel.

The emphasis on needing more information within the theme of parent preparation, points to problems that these parents have experienced in the past. Here they are connecting what they have fought to access under this idea with earlier themes of rapport and feedback. These groups of parents has taken the time and put in the effort to obtain information. Now they want to tell school personnel 
the importance of helping other parents to be prepared for IEP meetings. They also want to help prepare these parents themselves and to encourage other parents to become strong advocates.

5) Theme five: Procedural safeguards. The fifth theme, procedural safeguards, looked at how well participants understood procedural safeguards. The majority of parents reported that either they had no idea about these safeguards or did not fully understand them due to the complexity of the IEP process, the terminology used, and feeling that there was too much information on the papers they were given. Several participants reported that they were given "high stack of papers". However, they signed the form anyway because they wanted to go ahead with the IEP meetings. Three participants stated that the procedural safeguards document could be summarized into fewer pages. Other parents, such as Xavier (deaf), felt that he was presented with a "business proposal" when he saw the thickness of the procedural safeguards documents. Xavier reported that there were "too many pages [and that] it's silly... I was forced to look through too much". These five participants often asked for clarification due to the complexity of the procedural safeguards and other documents such as assessment reports and progress reports with IEP goals. Two deaf parents, Jose and Ana, reported that the "[school] would summarize what the papers meant".

Understanding the procedural safeguards of the IEP process was also difficult for Latino participants due to the "complexity of concepts and topics". A deaf participant, Irina, reported that she understood some of the information but "if there [was] something [that] [she] object [ed], [she had] the right to bring it up". However, Irina understood her rights and did not give up even if the IEP team thought differently, but she still did not fully comprehend all of the procedural safeguards. Irina reported:

I [made] sure my rights are acknowledged but I don't understand some of it... yes it was complicated even as they explained it to me. I just nodded along because I didn't understand what the words meant. I just had to follow the routine and sign my name on the procedural safeguards document. I also didn't understand the other documents. But it was fine. I just followed the routine.

All six participants stated that they understood their child's present levels of academic performance and goals. However, five participants stated they struggled with understanding IEP procedures, as it was too much information to read and understand all at once.

The theme of procedural safeguards found that parents felt that the terminology, complex concepts, and number of pages used in procedural safeguards did not allow them to effectively understand the IEP process. The majority of parents had difficulty understanding the concepts due to the advanced terminology and English not being their first language. They wanted to comprehend and be aware of what they were reading and signing to better advocate for their child- 
ren's academic success.

6) Theme six: Action. The sixth theme, action, focused on how parents were active in ensuring that their deaf children's services needs were met, including extracurricular activities. This theme also included how participants took action to request services such as ASL interpreters, addressed school personnel's lack of fluency in ASL, and worked with their child at home to meet educational goals. When participants wanted to meet their children's educational goals, deaf parents, Jose and Ana, requested an Assessment Intervention specialist to provide assistance for their deaf children to meet academic expectations. Jose and Ana also ensured that their request was met by having a counselor who was fluent in ASL, even if it meant using someone from another school district to provide the service at their children's school.

While four parents fought for qualified ASL interpreters to be provided for their children who attended mainstreamed programs in public schools, only three succeeded in having this need met. In addition, four parents requested increased quality of instruction, both at the mainstreamed programs and at schools for the deaf. However, three participants were not satisfied because the IEP team did not comply with their requests. These participants stated that they will continue to address the quality of instruction for their deaf children at the next IEP meeting.

A hearing parent, Lorena, reported that she paid attention to what was happening during her deaf child's education but if there was something that was not done, she took action and talked with the school who "[explained] why things [were] not done and what they [were] doing". Another hearing Spanish-speaking parent, Carlos, shared an experience he dealt with during an IEP meeting. There was an inexperienced member of the IEP team who did not have the ability to understand the IEP process. As a result, he petitioned the school board to have this member replaced and only use members who had experience and knowledge about IEPs.

Several parents shared examples of how they help their children meet educational goals at home. One example was that our deaf parent, Irina, interacted with her three deaf children daily, as they did homework assignments at home. Irina explained, "I placed vocabulary words on strips of paper all over the walls at my child's eye view levels in my house. Since I have three deaf children, I wanted to provide a print-rich environment for them to see everyday". Irina added that she read books, and talked and played with her deaf children to foster a close relationship with them, just like their siblings and friends. She also used dramatic play by impersonating characters in the books they read. Another example was with Julia (a hearing parent) who asked her younger son questions and looked for appropriate responses to monitor her son's comprehension. Julia elaborated:

It helps me notice if something is off or [if] something is wrong, or if the

IEP goals were followed... it is for me to pretty much guess what was on 
grade level or higher but I can monitor him based on my younger son's conversations, knowledge and ability to answer questions. Sometimes I played "dumb" and pretended not to know what a certain word meant by saying to her younger son, "never heard of that word. What does it mean? It really worked!"

Again, parents show their strong involvement in their children's education. They did not simply permit the school to make decisions. They had high expectations for their children and wanted the school system to provide the services that would permit their children to thrive. Their actions connect strongly to the next theme.

7) Theme seven: Network. The seventh theme, network, referred to how participants networked with other parents, deaf role models, and deaf mentors to better understand the IEP process and support their children. One example was shared by a deaf parent, Xavier, who reported:

Whenever I asked for [an] interpreter for school events, I became more connected with other parents, teachers and other people there because I would be a part of the community. At my son's elementary school, we always participated in the community events.

Julia (hearing parent) shared another example and reported, "I really think it is important as parents to interact with each other and it is sad that we don't". Julia added, "for [parents] to become culturally and linguistically aware, they need to partner with ASL mentors and deaf role models".

A deaf parent, Irina, was "fortunate [to be] part of a deaf family and [be] aware of educational options for [her] deaf children" when the topic of cochlear implants were discussed. She was approached by an audiologist twice who tried to persuade her to get a cochlear implant for her youngest child, but she declined. Deaf parents, Jose and Ana, also shared a similar experience. They added, "the IEP team treats us fairly. They realize [that] we know more. We are grateful for our friends because they advise us before IEP meetings. Based [on] the Assessment Intervention specialist's and my friends' advice, I can request services when we meet with the IEP team". Carlos (hearing parent) commented that he has "had [a] lot of support from the university. We do know how the system works. [With] experience and time, we know how the system works so we [did not] have to make other process[es]".

The synthesis of parents' involvement is again reflected here in the theme of network. Connecting with other parents and deaf role models allowed them to be more aware of educational options and opportunities for their deaf children. In addition, networking allowed participants to understand the IEP process better and support their children's academics when they interacted with other parents for advice or support.

8) Theme eight: Advocacy. The last theme, advocacy, focused on how participants advocated for their deaf child during the IEP process, as well as how they 
fought and negotiated for their child's rights to get the necessary services. Results found that the majority of participants were aware of ASL interpreting services available for their deaf children, but stated that their children had insufficient access to interpreters and support personnel with ASL fluency. One example was when a deaf parent, Xavier, fought to get access to ASL interpreters for his child's mainstreamed classes. Xavier explained to the IEP team at the meeting several incidents where his son had missed information during the class, and requested interpreters to meet his son's educational needs. Two other deaf parents, Jose and Ana, called for an IEP meeting and requested a speech therapist who was fluent in ASL for their child. The school district denied their request because a speech therapist with fluent ASL skills was not available at their child's school. With determination, Jose pointed out that there was in fact a speech therapist fluent in ASL available in a school district nearby. Irina always advocated for her children and one time she refused to allow the school to place her child in the average classroom; she expressed these concerns to the school and they moved her child's placement.

All six parents reported that negotiating with the IEP team was something that they experienced, and that clearly informing the team of their expectations and requests were not always met with success. One example was with a deaf father, Xavier, who stressed the importance of ASL interpreters for his hard of hearing son who uses both spoken and sign language. Xavier and his wife thought that their son's academic performance was average compared to his hearing peers until he had two deaf classmates who utilized ASL interpreters for History and Science. Their son realized that he missed information when he was able to compare the curricular content with spoken English, used by his teacher, and ASL, as conveyed by the interpreter. He informed his parents about the benefits he had with the use of an ASL interpreter, which was an accommodation given to his two deaf classmates. As a result Xavier and his wife fought to get ASL interpreters in their son's classroom by calling for several IEP meetings, but they were unable to convince the school district that their son needed ASL interpreters.

When parents developed advocacy skills from friends who are deaf educators, this skill helped these parents to effectively support and advocate for their children. As a result, the IEP team promptly addressed and honored Jose and Ana's (deaf parents) requests. Jose recalled from one of his IEP experiences:

It all goes well, they [The IEP team] treat us fairly. They realize [that] we know a lot... they know that we know what we are talking about and [they] can't ignore our requests.

The majority of parents expressed the need to have an advocate during IEP meetings. They believed that if they had an advocate, they would ask for more information prior to IEP meetings and not experience barriers to understanding the IEP process. 
Four parents experienced resistance from the IEP team. An example of this resistance was found in a hearing mother's, Julia, comment. The IEP team did not immediately honor her request for a real time note taker in the classroom, which would be recorded on a screen for her son to read. This request was initially denied as it was not seen as related to her son's hearing loss. This kind of accommodation supported her son's visual learning style. As a result of finally obtaining this support, he received a high school diploma and went to college. Julia also felt that her younger son was smart but was not reaching his full academic potential. She believed that the school provided instruction based on what they already had at the school district; yet they would not go beyond the minimum standards to maximize her child's academic potential. Through her advocacy, Julia emphasized to the IEP team that they needed to look at what was best for the child, not use the "cookie cutter" approach. The IEP team cannot force parents to follow one particular approach, which may work for others.

Another example of how a parent advocated for her three deaf children was when Irina (who is deaf) observed them in their classrooms. After her observations, she discussed their progress with their teachers and suggested other strategies. She also met with the principal to discuss performance reviews for her children's teachers if she felt that they ignored her suggestions. She reported that her motivation related to these experiences was to ensure that her children received the highest quality education.

The last theme, advocacy, clearly showed how parents were their children's best educational advocate whether they needed to negotiate or overcome resistance from school personnel. Parents ensured that their children had access to appropriate accommodations such as ASL interpreters and notetakers. As well, their advocacy skills enabled them to ensure that their children achieved positive educational outcomes. One can see the logical interrelationships among these themes.

\subsection{Axial Coding}

The eight interconnecting themes identified in open coding were reduced into three larger categories during axial coding; 1) collaboration, 2) comprehension, and 3) expectations.

Axial code 1: Collaboration. Under the first code of collaboration, three themes were included, rapport, feedback, and diversity. Collaboration focused on how participants interacted with school personnel and other parents, as well as which strategies were seen as the most effective. Strategies included developing relationships between participants and members of the IEP team, ensuring that participants thoroughly understood what was expected of them during the IEP process, and establishing a mutual understanding and respect among participants and members of the IEP team.

A common finding was on how to foster positive relationships between families and members of the IEP team participants; parents emphasized that school 
personnel should have expectations for high performance based on the deaf child's minds, not the fact that they were deaf. Parents wanted this collaboration to ensure their deaf children's educational progress, both at school and home. Interviewees advised other parents to invite other personnel who are familiar with Deaf culture or deaf education to the IEP team to become a support system for the family. They recommended Assessment Intervention specialists and deaf advocates, as examples to support the family and their decisions. Under the category of collaboration, parents encouraged others to ask a lot of questions about the IEP process. A vital part of this collaboration was the emphasis on physically attending IEP meetings, not using either an audio phone call or a video conference to substitute for their presence at the meeting. In order to believe that there was mutual understanding and respect among participants and members of the IEP team, participants felt the need to be "heard" and to have their ideas incorporated into the IEP. This collaboration happened when parents were able to ask questions freely. Collaboration was seen as involving respect by the school personnel, regardless of the families' race, sexual orientation, education, or religion.

Axial code 2: Comprehension. The second code, comprehension, included the themes of parent preparation and procedural safeguards, relating to knowledge of the IEP process and parental rights. Comprehension focused on what participants needed to know about the IEP process to effectively prepare for meetings. IEP documents are written in "legalese", which is difficult for lay people to understand. Participants commented on this issue and would have liked to have a translation of the procedures that was more "parent friendly". Common findings included interviewees encouraging other parents to gain knowledge of the IEP process by observing their deaf children in the classroom to help set appropriate goals. They encouraged parents to contact the IEP team in advance for the agenda, progress reports and evaluations.

Axial code 3: Expectations. The third code, expectations, included the last three themes of action, network, and advocacy. This code related to utilization of resources, which provide leverage to help deaf children receive appropriate services. It helps parents understand what is happening at school and how to support their child at home. Several participants monitored their deaf children's educational progress at home by frequently interacting with them to check for comprehension. They also following up on their homework assignments; thus setting high expectations for their children. The majority of the participants were aware of the interpreting services available for their deaf children; however, some participants wanted direct communication in ASL at school rather than indirect communication through interpreters for their children. Deaf educators served in the pivotal role of advocate, speaking up for deaf children. Additionally, parents wanted the IEP process to be specific for the needs of their child. They stated that using a "one size" or cookie cutter approach to meet all students' needs does not work for all deaf students. Parents wanted school person- 
nel to share these high expectations.

\subsection{Core Category}

The three axial codes were synthesized to determine the core category of "Giving Parents a Voice". All parents, even Julia who works within the school system, felt that they were "visitors" in their children's education and that school personnel took control. Parents wanted to collaborate and understand the processes involved in their children' education. All parents wanted the school personnel to have high expectations for their children and not see them as "broken hearing children". Parents wanted to provide insights and recommendations to better support other parents who would go through this process in the future. Their hope was to "teach" school personnel how to collaborate for the benefit of the child. When participants have a "voice" during the IEP process and IEP meetings, it empowers them to be an equal team member and positively supports their deaf children's education. A visual diagram is shown in Figure 1 to

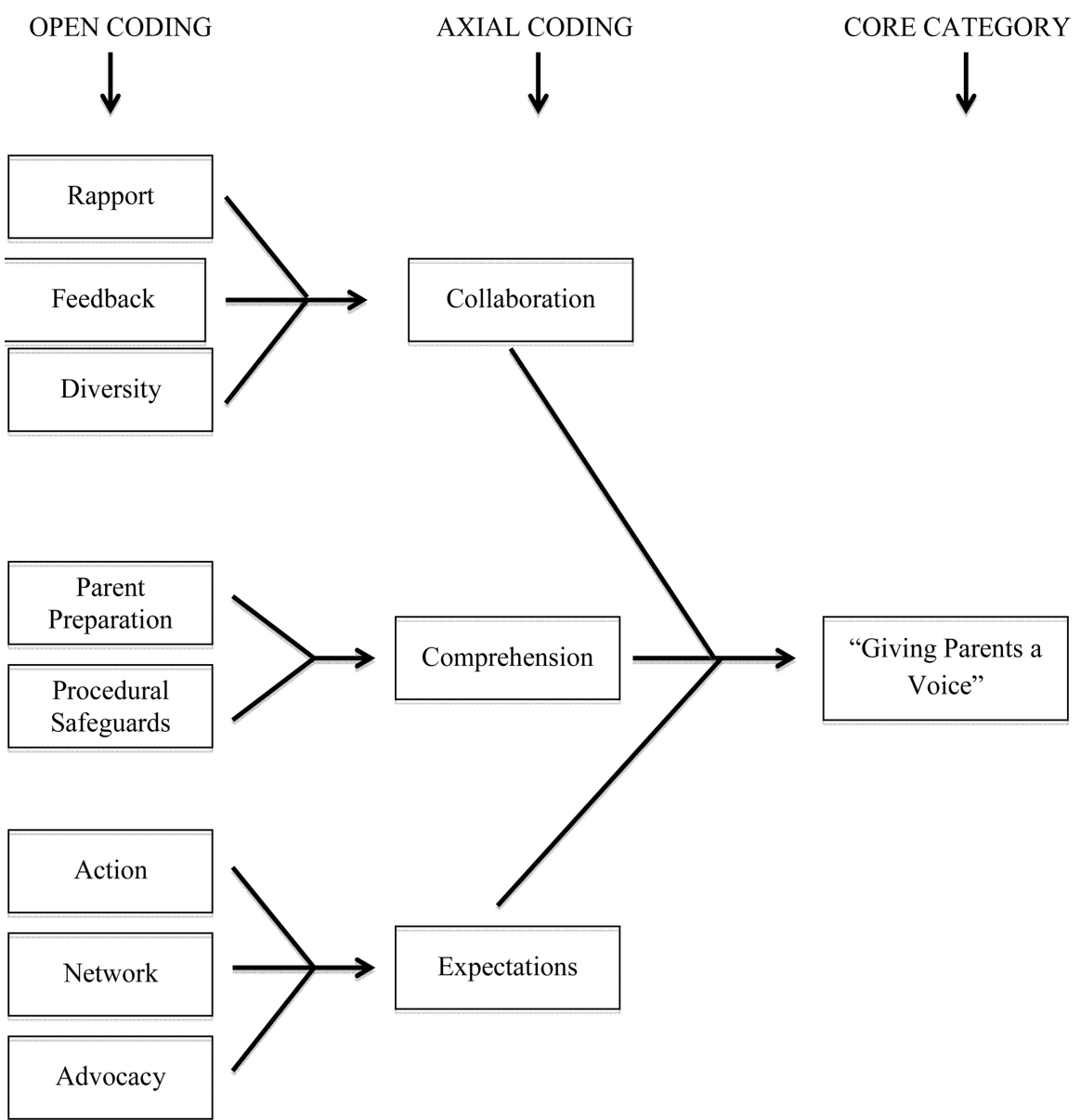

Figure 1. A grounded theory analysis is represented in a visual model. Open coding consists of eight themes while axial coding consist of three categories; collaboration, comprehension, and expectations. Each category contains either two or three themes from open coding. The core category of "giving parents a voice" was determined by the shared themes found in participants' experiences during the IEP process. 
summarize the results.

In summation, this core category showed participants' diverse experiences and perspectives of the IEP process. In addition, participants provided advice for other parents on how to navigate through the IEP process more efficiently and to better understand IEP meetings for the support their deaf children.

\section{Discussion}

The overarching findings here highlight the importance of "giving parents a voice" during the IEP process. When parents are seen as an equal member of the IEP team, they have a better understanding of this process. As well, they are more prepared and better informed about their children's educational progress. This collaboration needs to be equal and school personnel need to listen to parents and value their suggestions. If parents and school personnel follow the CEASD idea of Child First, more synergistic IEPs could be developed to be implemented for both school and home. Parents and school personnel then work together for more effective outcomes, as noted by Underwood (2010). Therefore, the issue of "giving parents a voice" was a critical component and overarching theme for participants to feel like an equal team member during IEP meetings, be respected for their opinions and concerns, be their child's best advocate, and achieve positive educational outcomes.

Child First (CEASD, 2012) discusses that each deaf child has unique needs and all of their needs and these specific needs should be the focus on the IEP. This idea in conjunction with IDEA supports the critical importance of parents' ability to comprehend IEP procedures (Easterbrooks et al., 2004). Easterbrooks et al. (2004) highlight that two or more members with extensive experience in the needs of deaf children are required in the new IDEIA regulations. This policy is an attempt to include parents in the decision making components of the development of the IEP. Underwood (2010) points out that not fully having a voice and understanding their parental rights disempowers parents in the IEP process. Therefore, what this study points to is the need for transparency in the legal process so that parents are able to advocate for their children while also providing the kinds of linguistic and academic support at home that will help their children succeed. However as noted by Knight (2010), parents frequently do not receive the necessary information to understand their rights. This lack of understanding leads parents to be dissatisfied with IEP meetings (Shah, 2012) and blocks parent-school personnel collaborations.

Child First (CEASD, 2012) attempts to reframe LRE from "least restrictive environment" into meaning a "language rich environment". The purpose of this shifting is to highlight that parents and their deaf children need to be heard when making decisions about what will best serve the family. Importantly, CEASD (who historically focused on sign language) and the OPTIONS schools (who have historically focused on spoken language) have come together in an attempt to provide the best for each child without arguing epistemology. These 
meetings have been ongoing for about three years and collaborations are developing that help parents avoid needing to "choose" between sign or spoken language when their child is identified as deaf. More work is ongoing and these meeting show great promise for deaf education and hopefully better collaborations between parents and school personnel.

When going deeper into the data, the results suggest limited, if any, collaboration between parents and school personnel. Parents did report some positive experiences with the IEP process, but they clearly had to work to get feedback and develop rapport with school personnel. Parents reported the importance of open communication and wanting to be involved with their child's education, rather than being a passive recipient of received knowledge from school personnel. As noted by Peralta (2013), parents desire for high academic achievement for their child is frequently blocked by insufficient collaboration with school personnel.

Parents also saw issues of diversity as problematic when trying to develop collaboration with school personnel. This study intentionally recruited families with signing children as well as some families where English was not the first language of the parents to better understand their perceptions of IEP meetings. Importantly, these parents felt that as English was not their native language they were either ignored by school personnel or seen as not equal partners. They reported a lack of respect and a feeling that school personnel "looked down on them" due to either the home language or their lack of a college education. Parents internalized these frequent non-verbal slights from the school personnel at IEP meetings and were concerned as they felt that they should be seen as an equal partner within the process.

Some parents explained that a positive rapport was established when they were provided with accessible communication, such as having a specialist who signs or an interpreter who was familiar with Deaf culture and ASL. This accessible communication allowed the IEP process to be smoother when there was mutual respect and support. However, there were miscommunications, frustrations, and disagreements between the IEP team and parents. As mentioned by Aldersley (2002), school placement decisions often happened during IEP meetings between parents and school personnel, but these decisions were not always appropriate to meet the linguistic and academic needs of deaf children.

Parents expressed the belief that if they had effective collaborations with the IEP team and were involved with their children's school, they could better support their children's educational outcomes. Shaffer (2010) found that the overall satisfaction levels of parents were higher when they were actively involved in the IEP process. Therefore, it critical that parents and school personnel have open communication and a strong collaboration. According to Mislan, Kosnin, Jiar, Said, \& Hamid (2011), Malaysian parents' voices were highly valued by the IEP team because in their culture there is a strong belief that extensive support at home encourages children to be successful. Therefore, collaborations with educational specialists who include parents can improve academic outcomes for children (Underwood, 2010). 
Given the importance of collaboration, school personnel need to actively listen, support, and collaborate with diverse parents regardless of cultural and linguistic backgrounds. Jung (2011) called attention to the importance of parents' voices who are from diverse cultural and linguistic backgrounds. Unfortunately, structural values and attitudes from school personnel act as barriers, lowering expectations for their children's academic achievement. One participant (Julia) shared that the IEP team needs to "respect parents".

Given that some of our parents were deaf ASL users, they were able to easily understand the needs of their children. This state of affairs is not the norm, because the majority of deaf children are raised by hearing parents (Karchmer \& Mitchell, 2003) who have never met a deaf individual until their own child (Benedict, 2013). Accordingly, these hearing parents were most likely to feel that school personnel were more aware of best educational practices. Unfortunately, school personnel do not always make the best decisions with appropriate class placement at mainstream schools for deaf children, if they hold a pathological view of deaf children. This approach often views deaf children as needing to be fixed and made normal (Benedict, 2011). In contrast in this study, parents perceived that school personnel did not understand how to best serve deaf children; this belief leads them to provide advice and support to other parents with deaf children.

One important piece of advice was that parents must understand the procedural safeguards in place through the law. They also stated that parents need to be prepared and strongly encouraged them to physically attend the IEP meeting so that they could take an active role. These parental suggestions were also found in Trainor (2010a), who noted that a deaf advocate was beneficial to parents and provided cultural and language mediation between deaf children, hearing parents, and school personnel. With input from deaf advocates and deaf mentors, parents can speak up to the IEP team and request specific services for their deaf children.

In a similar way, parents strongly emphasized that they must be proactive in understanding all of their legal rights (Easterbrooks et al., 2004). As noted by Maydosz \& Maydosz (2012) these policies and procedures need to be provided to parents in an understandable format. Lo (2012) stressed the importance of involving parents in the IEP goal planning with the consideration of their knowledge level and cross-cultural communication preferences. Accordingly, these documents need to be translated into more everyday language so that parents do not feel that it is a "business proposal" with complex concepts and topics. In a similar finding, Cawthon \& Caemmerer (2014) when investigating parental satisfaction found that a major issue was their inability to understand all of these legal rights. Providing more accessible information will increase parents' confidence and allow them to become more effective collaborators. Possible solutions for the complexity of these documents are to develop parental workshops with take home materials to help prepare them to become active advocates for their 
children.

As stated in the special education laws children are entitled to a free and appropriate education, also known as FAPE (Gartin \& Murdick, 2005). For this reason, parents have the right to ensure that expectations for their children will lead to high levels of academic achievement. All parents want to see their deaf children have positive educational outcomes and be successful. Cawthon \& Caemmerer (2014) asked parents about their own expectations for their children's educational outcomes and more than one third of their participants responded that they expected their children to complete a bachelor's degree. Unfortunately, about six percent of these parents only expected their children to get a vocational degree. This cycle of low expectations is all too often a major issue within deaf education (Santini, 2014; Simms, 2014). Parents in this study were committed to avoiding these types of expectations and were strong advocates for their children. As is common in Deaf culture (Holcomb, 2013), these parents wanted to support others-reflecting the communal nature of deaf people. They worked to develop networks to share their knowledge, and encouraged and supported others to take action in the education of their own children.

One possible solution to the low expectations of deaf children is to shift away from the pathological view and move to a Deaf epistemology (Holcomb, 2010) that focuses on visual access, visual language, and visual learning. Deaf children are visual learners and need access to visual language in a Deaf-centric learning environment, both at home and at school. Deaf children need to "see" what hearing children "hear" (Holcomb, 2010). When parents view deaf children through the lens of a Deaf epistemology, they can effectively support their children's visual learning styles (Hauser, O'Hearn, McKee, Steider, \& Thew, 2010), achieve positive educational success with their children (Holcomb, 2010), and reframe deaf children as positive with having multiple opportunities (Benedict, 2011).

\section{Recommendations}

The results of this study leads to several recommendations from parents on how to improve the IEP process. First, parents are often overwhelmed by the large number of school personnel at the meeting. To bring more balance, it is suggested that the IEP meetings include Deaf mentors and advocates who are used to being in this type of high stakes meeting. Deaf advocates with extensive training in the IEP procedures and professional meditators can advise parents on which step comes next. This change allows parents' confidence and their voices to be heard.

Parents are supposed to make the final decision on any changes the IEP team may recommend (Wright et al., 2010). But given the larger number of school personnel on the IEP team parents do not feel that their voice has equal weight. Therefore, if a consensus cannot be reached, parents should not sign the IEP until they are completely satisfied. Having the Deaf mentor or advocate can help 
with this issue as they can remind the parent(s) that if they are not satisfied, they do not need to sign. This inability for parents to obtain the accommodations that they feel are necessary should trigger an automatic appeal which must be resolved within a month of the original meeting. If these mechanisms cannot be implemented within the school's IEP policy, the National Association of the Deaf should be contacted to help the family and the school resolve the need for the requested accommodation.

Next, documents should be provided in simple and plain language that is easily understood by parents (Mandic et al., 2012) at an average reading level of sixth grade, rather than that of a ninth grade reading level. Additionally, the use of twelve point font, as opposed to seven to eight point font will make the documents easier to review (Fitzgerald, 2006). Parents in this study suggested a summary of only one or two pages to be developed and shared with parents to help them with their comprehension of the policies.

If school resources could be share more widely, rather than only having district resources available, parents could request more specific types of accommodations for their children. Each district will not be able to provide low-incidence resources but these could be leveraged from nearby districts. Identifying mechanisms that could permit schools to exchange goods and services would be beneficial to children, their families, and school personnel.

\section{Limitations and Future Research}

There were several limitations in this study including the sampling strategy, sample size, and criteria of participants. Only six parents with ten deaf children who resided in the Southwestern part of United States were included in this project. Therefore, this sample is not representative of all parents of deaf children across the United States. In order to have a diverse sample, other parents were not included; this choice allowed Spanish-speaking parents to be included. It is possible that parents whose first language is not English may have additional needs that were not detected in this study.

Moreover, the study was a qualitative study and therefore is not generalizable to larger populations. Given these findings, future research can use quantitative methods to strengthen these initial findings. Surveys would give more generalizability but would still only have descriptive and correlational data. Another possibility is focus groups with parents after IEP meetings in order to allow them to create additional resources that could be used for future IEP meetings.

It is worth developing the translations of these materials into parent-friendly language to encourage them to become equal partners in the IEP process. These materials could be converted into trainings to allow school personnel to help prepare parents to be effective advocates for their children. Parent-teacher associations could provide workshops with role-plays and scenarios so parents can develop negotiating skills and present evidence to demonstrate their deaf children's strengths (Trahan, 2016). This action would assist the IEP team in recom- 
mending goals to measure deaf children's abilities in a holistic approach, rather than solely based on test performance scores (Trahan, 2016). If procedural safeguards could be revised, using simpler language, parents would be able to participate more effectively during IEP meetings.

\section{Conclusion}

In conclusion, there are two important findings from this study. First parents, regardless of how much they work with schools, do not fully understand the IEP process. Next, parents' voices are frequently not "heard" when they request accommodations for their deaf child. Future research needs to clarify how to obtain collaborations between parents and school personnel, which place the Child First. Parents need to be seen as valued and equal partners with school personnel so that deaf children can maximize their linguistic, academic, and socio-emotional development.

\section{Acknowledgements}

The primary author wants to acknowledge M. Diane Clark and Ju-Lee A. Wolsey for their support and mentorship in this journey. Most important, the primary author wants to thank parents in this study who provided insights that led to breakthroughs for a more efficient and satisfying experience during the IEP process.

\section{References}

Aldersley, S. (2002). Least Restrictive Environment and the Courts. Journal of Deaf Studies and Deaf Education, 7, 189-199. https://doi.org/10.1093/deafed/7.3.189

Belt, C. M. (2013). American Sign Language Is Not English on the Hands. American Sign Language: History. http://www.lifeprint.com/asl101/topics/history8.htm

Benedict, B. (2013). How Early Intervention Can Make a Difference: Research and Trends. http://videocatalog.gallaudet.edu/?video $=17618$

Benedict, R. (2011). Early Intervention: The Missing Link. https://www.youtube.com/watch?v=h5ZqKMgXciU

Byington, T. A., \& Whitby, P. S. (2011). Empowering Families during the Early Intervention Planning Process. Young Exceptional Children, 14, 44-56. https://doi.org/10.1177/1096250611428878

Cawthon, S. W., \& Caemmerer, J. M. (2014). Parents' Perspectives on Transition and Postsecondary Outcomes for Their Children Who Are Deaf or Hard of Hearing. American Annals of the Deaf, 159, 7-21. https://doi.org/10.1353/aad.2014.0013

CEASD (Conference of Educational Administrators of Schools and Programs for the Deaf) (2012). The First Child Campaign. http://www.ceasd.org/child-first/child-first-campaign

Ceci, S. J. (1990). On Intelligence-More or Less: A Bio-Ecological Treatise on intellectual Development. London, England: First Harvard University Press.

Creswell, J. W. (2013). Qualitative Inquiry and Research Design: Choosing among Five Approaches (3rd ed.) Thousand Oaks, CA: Sage.

Darden, E. C. (2009). Top 5 Court Rulings on Education. American School Board Jour- 
nal, 196, 19.

Davidson, K., Lillo-Martin, D., \& Chen Pichler, D. (2014). Spoken English Language Development among Native Signing Children with Cochlear Implants. Journal of Deaf Studies and Deaf Education, 19, 238-250. https://doi.org/10.1093/deafed/ent045

DesGeorges, J. (2013). Individualizing Deaf Education Services: More Important than Ever Before. Odyssey: New Directions in Deaf Education, 14, 30-34.

Easterbrooks, S. R., Lytle, L. R., Sheets, P. M., \& Crook, B. S. (2004). Ignoring Free, Appropriate, Public Education, a Costly Mistake: The Case of FM \& LG versus Barbour County. Journal of Deaf Studies \& Deaf Education, 9, 219-227. https://doi.org/10.1093/deafed/enh023

Etscheidt, S. (2012). Complacency with Access and the Aggregate? Affirming an Individual Determination of Educational Benefit under the Individuals with Disabilities Education Act. Journal of Disability Policy Studies, 22, 195-207. https://doi.org/10.1177/1044207311410423

Fishman, J. A. (2012). Cultural Autonomy as an Approach to Sociolinguistic Power-Sharing: Some preliminary notions. International Journal of the Sociology of Language, 213, 11-46.

Fitzgerald, J. W. (2006). Parents' Rights in Special Education: The Readability of Procedural Safeguards. Exceptional Children, 72, 497-510. https://doi.org/10.1177/001440290607200407

Fram, S. (2013). The Constant Comparative Analysis Method Outside of Grounded Theory. The Qualitative Report, 18, 1-25. http://www.nova.edu/ssss/QR/QR18/fram1.pdf

Freel, B. L., Clark, M. D., Anderson, M. L., Gilbert, G. L., Musyoka, M. M., \& Hauser, P. C. (2011). Deaf Individuals' Bilingual Abilities: American Sign Language Proficiency, Reading Skills, and Family Characteristics. Psychology, 2, 18-23. https://doi.org/10.4236/psych.2011.21003

Gartin, B. C., \& Murdick, N. L. (2005). IDEA 2004 the IEP. Remedial and Special Education, 26, 327-331. https://doi.org/10.1177/07419325050260060301

Glesne, C. (2006). Becoming Qualitative Researchers: An Introduction. Boston, MA: Pearson Education, Inc.

Hart, B., \& Risley, T. R. (1975). Incidental Teaching of Language in the Preschool. Journal of Applied Behavior Analysis, 8, 411-420. https://doi.org/10.1901/jaba.1975.8-411

Hart, B., \& Risley, T. R. (1989). The Longitudinal Study of Interactive Systems. Education and Treatment of Children, 12, 347-358. http://www.jstor.org/stable/42899125

Hassanzadeh, S. (2012). Outcomes of Cochlear Implantation in Deaf Children of Deaf Parents: Comparative Study. The Journal of Laryngology and Otology, 126, 989. https://doi.org/10.1017/S0022215112001909

Hauser, P. C., O'Hearn, A., McKee, M., Steider, A., \& Thew, D. (2010). Deaf Epistemology: Deafhood and Deafness. American Annals of the Deaf, 154, 486-492. https://doi.org/10.1353/aad.0.0120

Holcomb, T. K. (2010). Deaf Epistemology: The Deaf Way of Knowing. American Annals of the Deaf, 154, 471-478. https://doi.org/10.1353/aad.0.0116

Holcomb, T. K. (2013). Introduction to American Deaf Culture. New York, NY: Oxford University Press.

Hrastinski, I., \& Wilbur, R. B. (2016). Academic Achievement of Deaf and Hard-of-Hearing Students in an ASL/English Bilingual Program. Journal of Deaf Studies and Deaf Education, 21, 156-170. https://doi.org/10.1093/deafed/env072 
Hyatt, K. J., \& Filler, J. (2011). LRE Re-Examined Misinterpretations and Unintended Consequences. International Journal of Inclusive Education, 15, 1031-1045. https://doi.org/10.1080/13603116.2010.484509

Jung, A. (2011). Individualized Education Programs (IEPs) and Barriers for Parents from Culturally and Linguistically Diverse Backgrounds. Multicultural Education, 18, 21-25. https://search.proquest.com/openview/1b5cc8ff7da448ff5c2cf8eae8f41602/1?pq-origsit $\underline{\mathrm{e}=\text { gscholar } \& \mathrm{cbl}=33246}$

Karchmer, M. A., \& Mitchell, R. E. (2003). Demographic and Achievement Characteristics of Deaf and Hard-of-Hearing Students. In M. Marschark, \& P. E. Spencer (Eds.), Oxford Handbook of Deaf Studies, Language, and Education (pp. 21-37). New York, NY: Oxford University Press.

Knight, J. A. (2010). When close Enough Doesn't Cut It: Why Courts Should Want to Steer Clear of Determining What Is-and What Is Not-Material in a Child's Individual Education Program. University of Toledo Law Review, 41, 375-409.

http://heinonline.org/HOL/LandingPage?handle=hein.journals/utol41\&div=21\&id=\&p age $=$

Leigh, I. W., \& Andrews, J. F. (2017). Deaf People and Society: Psychology, Sociology, and Education Perspectives (2nd ed.). New York, NY: Routledge.

Lo, L. (2012). Demystifying the IEP Process for Diverse Parents of Children with Disabilities. Teaching Exceptional Children, 44, 14-20. https://doi.org/10.1177/004005991204400302

Mandic, C. G., Rudd, R., Hehir, T., \& Acevedo-Garcia, D. (2012). Readability of Special Education Procedural Safeguards. The Journal of Special Education, 45, 195-203. https://doi.org/10.1177/0022466910362774

Maydosz, A., \& Maydosz, D. (2012). Culturally and Linguistically Diverse Students with Disabilities: Case Law Review. Multicultural Learning and Teaching, 8, 65-80.

McBride, H., \& Goedecke, M. (2012). Curriculum Modification: Making Standards Accessible for Deaf Students with Disabilities. Odyssey: New Directions in Deaf Education, 13, 8-11.

McKay, H. (2013). Hendrick Hudson Central School District v. Rowley (Provision of What Is an Appropriate Program). In Encyclopedia of Autism Spectrum Disorders (pp. 1502-1504). New York: Springer.

Mislan, N., Kosnin, A., Jiar, Y. K., Said, H., \& Hamid, D. T. A. H. (2011). Parents' Understanding on the Implementation of Individualized Education Programme. International Proceedings of Economics Development \& Research, 5, V2-406.

Moores, D. F. (2005). The No Child Left Behind and the Individuals with Disabilities Education Acts: The Uneven Impact of Partially Funded Federal Mandates on Education of Deaf and Hard of Hearing Children. American Annals of the Deaf, 150, 75-80. https://doi.org/10.1353/aad.2005.0028

More, C. M., \& Hart, J. E. (2013). Maximizing the Use of Electronic Individualized Education Program Software. Teaching Exceptional Children, 45, 24-29. https://doi.org/10.1177/004005991304500603

National Deaf Center on Postsecondary Outcomes. (2017). About Us. https://www.nationaldeafcenter.org/about-us

Olivos, E. M. (2009). Collaboration with Latino Families: A Critical Perspective of Home-School Interactions. Intervention in School and Clinic, 45, 109-115. https://doi.org/10.1177/1053451209340220

Peralta, C. (2013). Community, Home, and School Partnerships: A Critical Issue in Bi- 
lingual Education. Texas Education Review, 1, 48-58.

http://scholarworks.boisestate.edu/cgi/viewcontent.cgi?article=1074\&context=literacy= facpubs

Pittman, P., \& Huefner, D. (2001). Will the Courts Go Bi-Bi? IDEA 1997, the Courts, and Deaf Education. Exceptional Children, 67, 187-198. https://doi.org/10.1177/001440290106700204

Ruppar, A. L., \& Gaffney, J. S. (2011). Individualized Education Program Team Decisions: A Preliminary Study of Conversations, Negotiations, and Power. Research \& Practice for Persons with Severe Disabilities, 36, 11-22. https://doi.org/10.2511/rpsd.36.1-2.11

Santini, J. (2014). Reflections on Expectations. Odyssey: New Directions in Deaf Education, $15,74-78$.

http://www3.gallaudet.edu/Documents/Clerc/Odyssey/2014_issue/Odyssey2014_Santi ni.pdf

Shaffer, S. E. (2010). Parent Satisfaction with the IEP Process: Parents of Students with Mild Disabilities and Parents of Students with Severe Disabilities. Unpublished Master's Thesis, Athens, OH: Ohio University.

Shah, N. (2012). Special Education. Education Week, 31, 5. https://www.edweek.org/ew/articles/2012/02/22/21report-5.h31.html

Simms, L. E. (2014). The Power of Expectations: Two Stories. Odyssey: New Directions in Deaf Education, 15, 14-15.

http://www3.gallaudet.edu/Documents/Clerc/Odyssey/2014_issue/Odyssey2014_Simm $\underline{\text { s.pdf }}$

Solomon, A. (2012). Far from the Tree: Parents, Children and the Search for Identity (1st ed.). New York, NY: Scribner.

Steffan Jr., R. C. (2004). Navigating the Difficult Waters of No Child Left behind Act of 2001: What It Means for Education of the Deaf. American Annals of the Deaf, 149, 46-50. https://doi.org/10.1353/aad.2004.0017

Strauss, A. \& Corbin, J. (1990). Basics of Qualitative Research: Grounded Theory Procedures and Techniques. Newbury Park, CA: Sage.

Texas Education Agency (2014). Guidance on ARD Guide Production and Required Dissemination. http://www.tea.state.tx.us/index2.aspx?id=2147496922

Trahan, A. K. (2016). An Examination of Parental Experiences in the Individualized Education Plans of Their Deaf Children: A Qualitative Study. Doctoral Dissertation, Beaumont, TX: Lamar University.

Trainor, A. A. (2010a). Diverse Approaches to Parent Advocacy during Special Education Home-School Interactions Identification and Use of Cultural and Social Capital. Remedial and Special Education, 31, 34-47. https://doi.org/10.1177/0741932508324401

Trainor, A. A. (2010b). Reexamining the Promise of Parent Participation in Special Education: An Analysis of Cultural and Social Capital. Anthropology \& Education Quarterly, 41, 245-263. https://doi.org/10.1111/j.1548-1492.2010.01086.x

Underwood, K. (2010). Involving and Engaging Parents of Children with IEPs. Exceptionality Education International, 20, 18-36. http://ir.lib.uwo.ca/cgi/viewcontent.cgi?article $=1065 \&$ context $=$ eei

Vogt, W. P. (1999). Dictionary of Statistics and Methodology. Thousand Oaks, CA: Sage.

Wright, P. W., Wright, P. D., \& O'Connor, S. W. (2010). All about IEPs: Answers to Frequently Asked Questions about IEPs. Hartfield, VA: Harbor House Law Press. 